\title{
Binomial (Oran) Verilerin Meta-Analizi: Türkiye'deki İnternet Bağımlılık Oranının Belirlenmesi
}

\author{
Aslı KURT GENÇ ${ }^{1, \mathrm{a}}$ (D), Esin AVCI ${ }^{1, b^{*}}$ \\ 1 Giresun Universitesi, Fen Edebiyat Fakültesi, Istatistik Bölümü, Giresun, Türkiye
}

Geliş / Received: 31/03/2020, Kabul / Accepted: 23/09/2020

\begin{abstract}
Öz
Türkiye'de internet bağımlılı̆̆ı, internetin yaygın olarak kullanmaya başlanmasıyla ortaya çıkmıştır. Bu çalışmada, Türkiye'deki internet bağımlılık oranı, coğrafi bölge ve çalışılan gruplara göre bağımlılık oranlarının saptanması amaçlanmıştır. Dahil olma ve dışlanma kriterlerine göre toplam 71 adet çalışma ile meta-analiz yapılmıştır. Türkiye'de internet bağımlılık oranı \%13 (\%95 GA: 0.11; 0.14) olarak saptanmıştır. Bölgeler incelendiğinde; Ege ve İç Anadolu bölgesi \%17, Karadeniz \%14, Marmara \%13, Akdeniz \%11, Doğu Anadolu \%5 ve Güneydoğu Anadolu \%3 oranlarında internet bağımlılığı saptanmıştır. Çalışılan grup incelendiğinde; ortaokul $\% 5$, lise $\% 9$, ortaokul-lise $\% 30$, üniversite $\% 13$ oranlarında internet bağımlılığ saptanmıştır.
\end{abstract}

Anahtar Kelimeler: Binomial veri, İnternet bağımlılığı, Meta-analizi, metaprop

Binomial (Proportion) Data Meta-Analysis: Determination of the Internet Addiction Proportion in Turkey

\begin{abstract}
Internet addiction in Turkey has emerged as the Internet has become widely used. In this study, it was aimed to determine the internet addiction proportion and the proportion according to geographical region and studied groups in Turkey. A meta-analysis was conducted with a total of 71 studies according to inclusion and exclusion criteria. Internet addiction proportion in Turkey was determined as $13 \%$ (95\% CI: $0.11 ; 0.14$ ). When the regions were examined the proportions were respectively for Aegean and Central Anatolia regions 17\%, the Black Sea 14\%, Marmara 13\%, Mediterranean 11\%, Eastern Anatolia 5\% and Southeastern Anatolia $3 \%$. According to the studied group, the proportion was 5\% for middle school, $9 \%$ for high school, 30\% for junior high school and $13 \%$ for university.
\end{abstract}

Keywords: Binomial data, Internet addiction, Meta-analysis, metaprop

Bu makale Aslı Kurt Genç'in Giresun Üniversitesi Fen Edebiyat Fakültesi Matematik Anabilim Dalında Fen Bilimleri Enstitüsü’ne bă̆ll olarak Yüksek Lisans Tezinden türetilmiştir. 


\section{Giriş}

Temelleri 1960'lı y1llarda Amerika'da atılan internet tüm dünyaya hızla yayılmış ve 31 Mart 2017 tarihli verilerine göre 3.731.973.423 kişiye ulaşmıştır. 2000 ile 2017 yılları arasında \%933.8 internet kullanımı artmıştır. Türkiye'de de hızlı bir artış söz konusudur. 2005 yılında 7.270.000 internet kullanıcıs1, 2010 y1lında 35.000 .000 internet kullanıcısına sahipken 31 Mart 2017 tarihli verilere göre Türkiye'de 46.282.850 internet kullanıcıya ulaşmıştır. Benzer sayıda sosyal ağ kullanıcısı bulunmaktadır (Internet World Stats, 2017).

İnternet bağımlılığı, İngiltere'de 1991 yılında Shotton'un bilgisayar bağımlılı̆̆1 ve 1996 y1lında Griffiths teknoloji bağımlılığ1 eğilimleri üzerindeki çalışmalarından sonra, Ivan Goldberg tarafindan ilk kez terim olarak kullanılmıştır. İnternet bağımlılığıyla ilgili ilk ölçek çalışması 1996 yılında Young tarafından yürütülmüştür (Young, 2004). Bu ölçek Amerikan Psikoloji Derneği'nin (American Psychological Association) Zihinsel Bozukluklar Tanı ve İstatistik Kılavuzu'nun dördüncü baskısı (DSM-4) esas alınarak hazırlanmıştır. 5'li likert ölçeğinden yararlanılarak puanlama yapılmış 80 ve üzeri puan alanlar patolojik; 50-79 aras1 puan alanlar sinırlı semptom gösteren ve 49 ve altı puan alanlar semptom göstermeyen internet kullanıcısı olarak tanımlanmıştır (Bayraktar, 2001).

İnternet, uygun bir biçimde kullanılmadığında insan yaşamını olumsuz etkiler ve bağımlılık oluşturabilmektedir. İnsanların çoğu ihtiyaçlarını karşılayan internet, gereğinden fazla kullanıldğında bağımlılığın gelişmesine neden olmaktadır (Morahan-Martin ve Schumacher, 2000). İnternetin yaygınlaşmasıyla, özellikle gelişmiş ve gelişmekte olan ülkelerde okul ve ev dişında sosyal ortamların kısıtlı olması; kolay erişim sağlayan çocuklar ve ergenlerin internet kullanımını bu yaş gruplarında arttırmıştır (Muslu ve Bolisik, 2009).

Doğru internet kullanımı, bilgi derleme, okuma, yazma, seçme, sınıflandırma gibi çeşitli becerilerin edinimini sağlarken, hatalı internet kullanımı ise sinir bozukluğu, psikolojik rahatsızlık, sosyal problemlere neden olmaktadir (Caplan, 2002). İnternet bağımlısı olarak tanımlanan bireylerde, sosyal ilişkilerin azaldığ 1 ve iletişimde sorun yaşadı̆̆ı saptanmıştır (Welsh, 1999; Shim, 2004).

$\mathrm{Bu}$ çalışmada, Türkiye'deki internet bağımlılık oranı, Türkiye'nin coğrafi bölgelerine göre internet bağımlılık oranı ve çalışılan gruba göre internet bağımlılık oranı meta-analiz yardımıla saptanması amaçlanmıştır.

\section{Materyal ve Metot}

Belirli bir konuda birbirinden bağımsız ve farklı çalışmalardan elde edilen ve aynı biçimde raporlanan bilgilerin sentezlenmesine meta-analizi denilmektedir (Borenstein vd., 2009).

1904 yılında ilk meta-analiz uygulaması Karl Person tarafından yapılmıştır (Pearson, 1904). Meta-analiz, 1930'lu yıllarda benzer çalışmaların birleştirilmesi, 1940'l1 yıllarda ise farklı çalışmaların birleştirilmesi olarak ele alınmış, 1970'li yıllarda sosyal bilimlerde yaygin olarak (Rosenthal ve Rubin, 1978; Schmidt ve Hunter, 1977) ve 1980'li yıllarda geçmiş ile var olan durum karşılaştırmalarında kullanılmıştır (Glass vd., 1981; Hedges ve Olkin, 1985; Hunter vd.,1982; Rosenthal, 1984). 
Meta-analizinin her bilimsel araştırma yöntemi gibi kendine özgü bir süreci vardır. Konu, literatür tarama, ölçütlerin belirlenmesi, konunun belirlenmesi, araştırma sorularının belirlenmesi, kodlama, analiz, etki büyüklüğünün hesaplanmas1, heterojenlik testi, modelin seçimi, genel etkinin hesaplanması ve yorumlamadan oluşmaktadır. Süreç on iki aşamada belirlenmektedir. $\mathrm{Bu}$ aşamalardan sonra kontroller yapılmaktadir. Yapılan kontrollerde hata görülmesi durumunda ilgili basamağa dönüş yapılarak basamaklar tekrarlanmaktadır. Çalışma deseni ve derlenme şekline göre genel etki, sabit etki ya da rastgele etkiler modeline göre hesaplanmakta ve sonuçlar yorumlanmaktadir.

Etki büyüklüğü, iki değişken arasındaki ilişki miktarı veya iki grup arasındaki farklılığın miktarında kullanılan hesaplama değeridir. Etki büyüklüğü, 1977 yılında ilk defa Cohen tarafından geliştirilmiştir (Deeks, 2002).

Sabit etkili model, etki büyüklükleri arasındaki farklılıklarının çalışma içi değişkenlikten (örneklem hatasından) kaynaklandığını ve çalışma sonuçları arasında heterojenliğin olmadığını varsaymaktadır (Sutton vd., 2000). Rastgele etkili model ise, etki büyüklükleri arasındaki farklılıklarının çalışma içi değişimin yanı sıra çalışmalar arası değişimden $\left(\tau^{2}\right)$ kaynaklandığını varsaymaktadır (Borenstein vd., 2009).

Meta- analiz çalışmalarında heterojenliğin iki sebebi vardır: Birincisi örneklem hatası (çalışma içi değişkenlik) ikincisi çalışmalar arasındaki değişkenliktir (Huedo-Medina vd., 2006). Heterojenlik analizi, etki büyüklüklerinin bir çalışmadan diğer bir çalışmaya nasıl değiştiğini göstermektedir.
Bir meta-analizinde sonuçların birleştirilmesinden sonra heterojenlik için istatistiksel testlerin ve grafiksel gösterimlerin incelenmesi gerekmektedir. Heterojenliğin istatistiksel olarak anlamlı olup olmadığını bulmak için en çok Q ve $\mathrm{I}^{2}$ istatistikleri kullanılmaktadır (Bailer ve Mosteller, 1992). Heterojenliğin ortaya çıkarılmasında alt grup ve meta-regresyon yöntemleri kullanılmaktadır (Dinçer, 2013).

Yayın yanlılığ1, literatür taraması yapıldığında çalışılan alandaki her çalışmaya ulaşılamaması halinde ortaya çıkan bir olaydır. Çalışmaların sadece yayınlanmış ve anlamlı bulunmasiyla meta-analizine katılan kaynakların yayın yanlılığı olup olmadığını kontrol etmek için funnel grafiği (huni grafiği) kullanılır. Rank korelasyon testi, funnel grafiği yorumlarındaki farklılığ ortadan kaldırmak için kullanılan bir testtir (Deeks, 2002). Yayın yanlılığının net bir şekilde anlaşılması için en kesin yol gerçek etki büyüklüğünün varyansı olan $\tau^{2}$ katsayısıdır. $\tau^{2}$ katsayının 1'e yakın olması ve $p$ değerinin anlamlı olmaması durumunda yayın yanlılığının olmadığını göstermektedir (Dinçer, 2014). Egger (1997) funnel grafiğinin asimetrisini test etmek için doğrusal regresyon testi önermiştir. Standart etki tahminleri ile standart hata arasındaki ilişkiyi değerlendirmektedir. Rank korelasyon testine göre daha güçlü bir testtir (Deeks, 2002).

\subsection{Oran için Meta-Analizi}

Bir araştırmada bazı unsurlar göz ard1 edilerek önemli olan olgu ya da olay incelenmesinde kavramsal olarak birbirine zit, ters veya tamamlayan kavramlar ortaya çıkabilir. Bu tür kavramların analizinde ikili veriler kullanılır. 
$\begin{array}{lcr}\text { Meta-analizinde } & \text { oran } & \text { verilerinin } \\ \text { modellenmesinde } & \text { üç } & \text { yaklaşım } \\ \text { kullanılmaktadır. En çok kullanılan yaklaşım } \\ \text { normal dağılım yaklaşımıdır. Diğer iki }\end{array}$ normal dağılım yaklaşımıdır. Diğer iki yaklaşım ise logit ve arcsinüs yaklaşımlarıdır (Nyaga vd., 2014).

Oran için meta-analizi uygulandığında çalışmalardan elde edilen oranlar farklı yöntemlerle birleştirilerek, birleştirilmiş oran değeri tahmin edilir. Genel olarak metaanalizinde ters-varyans yöntemine dayalı olarak oran hesaplanır,

$\operatorname{Var}(p)=\frac{p q}{N}$

Birleştirilmiş oran değeri de buna göre hesaplanır,

$P=\frac{\sum_{i} \frac{p_{\mathrm{i}}}{\operatorname{Var}\left(p_{\mathrm{i}}\right)}}{\sum_{i} \frac{1}{\operatorname{Var}\left(p_{\mathrm{i}}\right)}}$

Oranın tanım aralığı dışına çıkamaması ve her bir çalışmanın olması gerektiğinden fazla ağırlı almaması için oran üzerinde dönüşümler uygulanarak ters-varyans yöntemi ile meta-analizi uygulanabilir (Barendregt vd., 2013). Oran değerinin 0.5 etrafında olması durumunda normal dağılım yaklaşımı doğru sonuç verse de oran değerlerinin 0 veya 1 'e yaklaşması durumunda yani çok küçük veya büyük değer alması varyans değerinin 0'a doğru yoğunlaştırmaktadır. $\mathrm{Bu}$ durumda etki büyüklüğünün dağılımını normalleştirmek için oranların doğal logaritması (log) alınarak birleştirilmiş oran elde edilir (DerSimonian ve Laird, 1986; Zhang vd., 2011; Horikawa vd., 2011). Meta-analizi uygulandiktan sonra uygulanan dönüşümler orana dönüştürülmelidir (Zhang vd., 2011). S1kça kullanılan logit dönüşümü, oranın 0 ve 1 arasında yer almasını sağlasa da varyansın sabitlenmesini sağlamamaktadır. Logit dönüşümü için varyans,

$\operatorname{Var}(\operatorname{logit}(p))=\frac{1}{N p}+\frac{1}{N q}$

Burada, N, kitle hacmini belirtmektedir (Barendregt vd., 2013).

Değişen varyans durumunda en çok kullanılan dönüşüm yöntemi arcsinüsdür (http://strata.uga.edu/8370/rtips/proportions.h $\underline{\mathrm{tml}}$ ). Arcsinüs dönüşümü, oran verilerinin dönüştürülmesinde uygun bir yöntemdir. Binom dağılımına sahip olan oran verilerine arcsinüs dönüşümü, ters- varyans yöntemini kullanarak normal dağılıma yaklaştırmaktadır. Arcsinüs dönüşümünde sonuçlar radyan ve derece cinsinden ifade edilir (Sokal ve Rohlf, 1995). Arcsinüs dönüşümü orana ait güven aralığının 0 ile 1 arasında olmasını aynı zamanda varyansın da sabitlenmesini sağlamaktadır (Hanlon ve Larget, 2011). Arcsinüs dönüşümü için varyans, Taylor serisinin açılımıyla elde edilen delta yönteminden hesaplanmaktadır (Shao, 1998).

$\operatorname{Var}(\arcsin \sqrt{p}) \approx \frac{p q}{4 n p q}=\frac{1}{4 n}$

Tek oran için güven aralıklarının elde edilmesinde Vollset çeşitli yöntemler önermiştir. En sık kullanılan tek oran (p) için güven aralığı (Vollset'in Wald yöntemi $(p \pm z \sqrt{p q / n})$ normal dağ 1 lım yaklaşımından elde edilmiştir (Vollset, 1993). Güven aralığının oluşturulmasında bir diğer yaklaşım süreklilik düzeltmesinden yararlanılarak elde edilmektedir. $\mathrm{Bu}$ düzeltme terimi $\mp 0.5$ değeri kullanılarak yapilır.

$p \pm\left(z \sqrt{\frac{p q}{n}}+\frac{1}{2 n}\right)$ 
Burada, $z, 1-\alpha / 2$ güven düzeyinde standart normal dağılım değeridir (Blyth ve Still, 1983).

\section{Bulgular}

\subsection{Verilerin Toplanması}

Bu çalışmada, Türkiye'de internet bağımlılığ konusunda yayımlanan çalışmalar metaanalizi ile incelenmiştir. 5 farklı veri tabanından "internet bağımlılı̆̆ı", "internet addiction", "problematic internet use", "problemli internet kullanımı", "IAS”, “IBÖ" anahtar kelimeleri ile yapılan araştırma sonucunda 4255 adet yayına ulaşılmıştır. Meta-analizine dahil edilecek çalışmaların dilinin Türkçe ve İngilizce olarak Türkiye'de yapılmış ve bağımlı kişi sayısının raporlanmış olmasına dikkat edilmiştir. Deneysel çalışmalar (araştırmacı tarafından bağımlı-bağımlı olmayan gruplarında yer alacak kişilerin belirlendiği) ve tek vaka çalışmaları analiz dışında tutulmuştur. Çalışmalar arasındaki heterojenlik, alt grup analizi ile saptanmıştır.

\subsection{Verilerin Kodlanması}

Tablo 1.'de ele alınan çalışmalar gösterilmiştir. Her bir çalışmanın yazar ve yıl bilgisi, Türkiye'deki internet bağımlılığı olan kişi sayısı, çalışılan örneklem hacmi, Türkiye'nin coğrafi bölgeleri ve çalışılan grup yer almaktadır.

\section{3. Çalışma Karakteristikleri}

Türkiye'deki internet bağımlılık oranının belirlenmesi çalışmasında Meta-analizine dahil edilen çalışma sayısı ve bu çalışmanın temel bilgileri Şekil 1'deki kriterlere göre uygulanmıştır. Türkiye'nin farklı illerinde yapılan 71 çalışma ele alınmıştır.

\subsection{Verilerin Analizi}

$\mathrm{Bu}$ çalışmada, verilerin analizinde, oran için meta-analizi yöntemi kullanılmıştır. $\mathrm{Bu}$ araştırmada, Türkiye'deki internet bağımlılık oranının belirlenmesi için $\mathrm{R}$ programının "metaprop" fonksiyonuna ile Microsoft Excel 2016 programı kullanılmıştır. Çalışmada R programının "metaprop" fonksiyonundan yararlanılarak binomial verilerin oranı için meta-analizi sonuçları elde edilmiştir.

\subsection{Türkiye'deki İnternet Bağımlılık Oranı}

Türkiye'deki internet bağımlılık oranının belirlenmesinde 71 adet çalışma incelendiğinde toplamda 48134 kişiden oluştuğu görülmüştür. Çalışmalardan 66's1 2010 yılı ve sonrasında yapılmıştır. Konu ile ilgili çalışmalar en çok İç Anadolu (16), Marmara (11) ve Karadeniz (9) ile Akdeniz (9) bölgelerinde yapılmıştır. İnternet bağımlılığı ile ilgili çalışmalar daha çok üniversite (30) ve lise (27) gruplarıla yapılmıştır.

Çalışmaların homojenliğinin test edilmesinde $\mathrm{Q}$ ve $\mathrm{I}^{2}$ istatistiklerinden yararlanılmıştır $(\mathrm{Q}=$ 4863.67 ve $I^{2}=\% 99.9$ ). Çalışmalardaki etki büyüklüklerinin eşitliği hipotezi \%95 güvenle reddedilmiştir $(\mathrm{p}<0.05)$ ve çalışmaların heterojen olduklarına karar verilmiştir.

Ele alınan çalışmalar yayınlanmış literatürden derlendiğinden birleştirilmiş oranın (etki büyüklüğü) hesaplanması için rastgele etki modelin kullanılması daha uygun olduğu görülmüştür.

71 çalışmada yayın yanlılığı olup olmadığını incelemek için huni (funnel) grafiğinden yararlanılmıştır (Şekil 2). 
Tablo 1. Meta-analizine alınan çalışmaların bilgileri

\begin{tabular}{|c|c|c|c|c|c|}
\hline No & Çalışma (Yazar, Yıl) & $\begin{array}{c}\text { İnternet Bağımlılığı Olan } \\
\text { Kişi Sayısı } \\
\end{array}$ & $\begin{array}{l}\text { N (Çalışılan Örneklem } \\
\text { Hacmi) }\end{array}$ & Bölge & $\begin{array}{l}\text { Çalıșılan } \\
\text { Grup }\end{array}$ \\
\hline 1 & Aslan ve Yazıcı (2016) & 18 & 702 & Akdeniz & Üniversite \\
\hline 2 & Ertekin vd. (2016) & 2 & 257 & Marmara & Ortaokul \\
\hline 3 & Şimşek vd. (2015) & 13 & 358 & Diğger & Lise \\
\hline 4 & Morsünbül (2014) & 72 & 388 & İç Anadolu & Üniversite \\
\hline 5 & Alaçam vd. (2015) & 181 & 2096 & Ege & Üniversite \\
\hline 6 & Batıgün ve Kılıç (2011) & 189 & 1198 & Diğer & Üniversite \\
\hline 7 & Durualp ve Çiçekoğlu (2013) & 8 & 47 & İç Anadolu & $\begin{array}{l}\text { Ortaokul, } \\
\text { Lise }\end{array}$ \\
\hline 8 & Balcı ve Gülnar (2009) & 221 & 953 & İç Anadolu & Üniversite \\
\hline 9 & Köksal (2015) & 15 & 401 & Akdeniz & Üniversite \\
\hline 10 & Gökçearslan ve Günbatar (2012) & 4 & 172 & Marmara & Lise \\
\hline 11 & Mayda vd. (2015) & 397 & 698 & Karadeniz & Üniversite \\
\hline 12 & Ergin vd. (2013) & 3 & 386 & Ege & Üniversite \\
\hline 13 & Durak Batıgün ve Hasta (2010) & 30 & 213 & İç Anadolu & Üniversite \\
\hline 14 & Çiğdem ve Yarar (2015) & 76 & 731 & Diğer & Üniversite \\
\hline 15 & Günüç (2013) & 59 & 165 & Diğer & $\begin{array}{l}\text { Ortaokul, } \\
\text { Lise }\end{array}$ \\
\hline 16 & Yilmaz vd. (2014) & 465 & 2853 & Marmara & Lise \\
\hline 17 & Zirhlıoğlu (2011) & 15 & 1084 & Doğu Anadolu & Lise \\
\hline 18 & Eldeleklioğlu vd. (2013) & 1 & 206 & Diğer & Lise \\
\hline 19 & Gezgin ve Akıllı (2016) & 15 & 501 & Diğger & Lise \\
\hline 20 & Çam ve Nur (2015) & 74 & 1045 & Karadeniz & Lise \\
\hline 21 & Canan vd. (2012) & 101 & 1028 & Karadeniz & Üniversite \\
\hline 22 & $\begin{array}{c}\text { Dalbudak ve Evren (2014); Dalbudak } \\
\text { vd. (2014) }\end{array}$ & 54 & 271 & İç Anadolu & Üniversite \\
\hline 23 & Şenormanc1 vd. (2014) & 52 & 720 & Karadeniz & Üniversite \\
\hline 24 & $\begin{array}{l}\text { Dalbudak vd. (2013); Dalbudak vd. } \\
\text { (2013) }\end{array}$ & 39 & 319 & İç Anadolu & Üniversite \\
\hline 25 & Seyrek vd. (2017) & 77 & 432 & İç Anadolu & $\begin{array}{l}\text { Ortaokul, } \\
\text { Lise }\end{array}$ \\
\hline 26 & Kesici ve Şahin (2009) & 162 & 384 & İç Anadolu & Üniversite \\
\hline 27 & Aktepe vd. (2013) & 237 & 1645 & Akdeniz & Lise \\
\hline 28 & Ekinci vd. (2014) & 31 & 1212 & Akdeniz & Lise \\
\hline 29 & Öztürk vd. (2013) & 20 & 303 & Doğu Anadolu & Lise \\
\hline 30 & Dalbudak vd. (2015) & 64 & 582 & İç Anadolu & Üniversite \\
\hline 31 & Boysan vd. (2017) & 43 & 455 & Diğer & Üniversite \\
\hline 32 & Öztürk vd. (2015) & 121 & 328 & Ege & Lise \\
\hline 33 & Canan vd. (2017) & 102 & 652 & Akdeniz & Üniversite \\
\hline 34 & Koyuncu vd. (2014) & 91 & 1157 & İç Anadolu & Lise \\
\hline 35 & Kilıç vd. (2016) & 226 & 1742 & Diğer & Lise \\
\hline 36 & Alpaslan vd. (2015) & 39 & 220 & Ege & $\begin{array}{l}\text { Ortaokul, } \\
\text { Lise }\end{array}$ \\
\hline 37 & Alpaslan vd. (2015) & 59 & 584 & Ege & Lise \\
\hline 38 & Eliaçık vd. (2016) & 48 & 135 & Ege & $\begin{array}{l}\text { Ortaokul, } \\
\text { Lise }\end{array}$ \\
\hline 39 & Bozkurt vd. (2016) & 85 & 437 & Karadeniz & Diğer \\
\hline 40 & Bozoğlan vd. (2013) & 89 & 384 & İç Anadolu & Üniversite \\
\hline 41 & Şaşmaz vd. (2013) & 175 & 1156 & Akdeniz & Lise \\
\hline 42 & Evren vd. (2014) & 791 & 4957 & Marmara & Lise \\
\hline
\end{tabular}


Tablo 1. devam

\begin{tabular}{|c|c|c|c|c|c|}
\hline No & Çalışma (Yazar, Yıl) & $\begin{array}{c}\text { İnternet Bağımlılığı Olan } \\
\text { Kişi Sayısı }\end{array}$ & $\begin{array}{c}\text { N (Çalışılan Örneklem } \\
\text { Hacmi) }\end{array}$ & Bölge & $\begin{array}{l}\text { Çalışılan } \\
\text { Grup }\end{array}$ \\
\hline 43 & Gür vd. (2015) & 83 & 549 & Diğger & Ortaokul \\
\hline 44 & Yilmaz vd. (2015) & 97 & 640 & İç Anadolu & Lise \\
\hline 45 & Canan vd. (2014) & 67 & 1938 & Karadeniz & Lise \\
\hline 46 & Canan vd. (2010) & 34 & 292 & Karadeniz & Lise \\
\hline 47 & Baysan-Aslan vd. (2016) & 150 & 1107 & İç Anadolu & Üniversite \\
\hline 48 & Say ve Batıgün (2016) & 66 & 402 & Diğer & Üniversite \\
\hline 49 & Kır ve Sulak (2014) & 4 & 337 & Akdeniz & Üniversite \\
\hline 50 & Gümüş vd. (2015) & 14 & 375 & Diğger & Üniversite \\
\hline 51 & Günüç ve Kayri (2010) & 76 & 754 & Diğer & Lise \\
\hline 52 & Günüç ve Kayri (2009) & 31 & 253 & Doğu Anadolu & Üniversite \\
\hline 53 & Şahin vd. (2013) & 83 & 573 & Marmara & Üniversite \\
\hline 54 & Metin vd. (2015) & 61 & 771 & Karadeniz & Lise \\
\hline 55 & Şahin (2014) & 6 & 328 & Marmara & Üniversite \\
\hline 56 & Bozkurt vd. (2013) & 36 & 60 & Marmara & $\begin{array}{l}\text { Ortaokul, } \\
\text { Lise }\end{array}$ \\
\hline 57 & Eroğlu vd. (2015) & 80 & 160 & Akdeniz & $\begin{array}{l}\text { Ortaokul, } \\
\text { Lise }\end{array}$ \\
\hline 58 & İlhan vd. (2016) & 22 & 286 & Akdeniz & $\begin{array}{l}\text { Ortaokul, } \\
\text { Lise }\end{array}$ \\
\hline 59 & Gündoğar vd. (2012) & 33 & 304 & Diğer & Lise \\
\hline 60 & Taymur vd. (2015); Budak vd. (2015) & 27 & 185 & Marmara & Üniversite \\
\hline 61 & Önen vd. (2014) & 8 & 230 & $\begin{array}{l}\text { Güneydoğu } \\
\text { Anadolu }\end{array}$ & Lise \\
\hline 62 & Üneri ve Tanıdır (2011) & 51 & 211 & İç Anadolu & Lise \\
\hline 63 & Canbaz vd. (2009) & 10 & 810 & Karadeniz & Lise \\
\hline 64 & Ekinci (2014) & 22 & 371 & Marmara & Üniversite \\
\hline 65 & Şahin ve Deniz (2013) & 9 & 710 & Diğer & Ortaokul \\
\hline 66 & Akdağ vd. (2014) & 17 & 1325 & Doğu Anadolu & Üniversite \\
\hline 67 & Taymur vd. (2016) & 34 & 212 & Marmara & Üniversite \\
\hline 68 & Günüç (2015) & 14 & 131 & Doğu Anadolu & Lise \\
\hline 69 & Usta vd. (2014) & 22 & 354 & İç Anadolu & Diğer \\
\hline 70 & Aslanbay vd. (2009) & 25 & 313 & Marmara & Lise \\
\hline 71 & Şahin (2011) & 2 & 596 & İç Anadolu & Diğger \\
\hline Toplam & & 5748 & 48134 & & \\
\hline
\end{tabular}

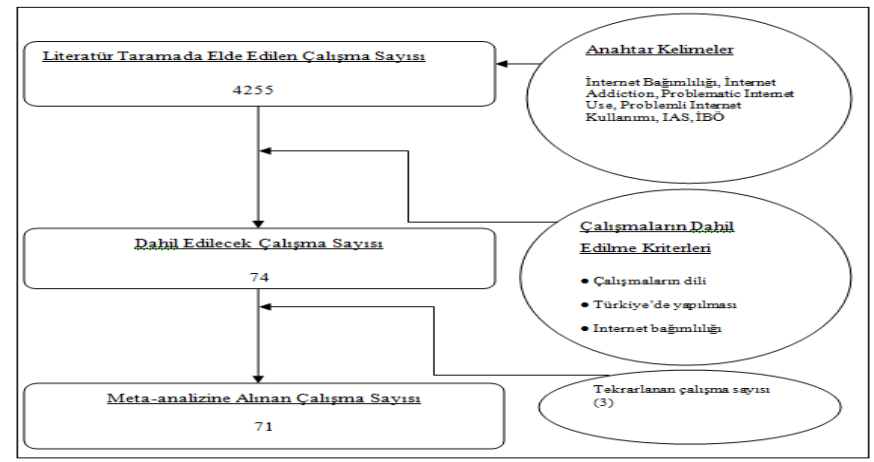

Şekil 1. Akış şeması 


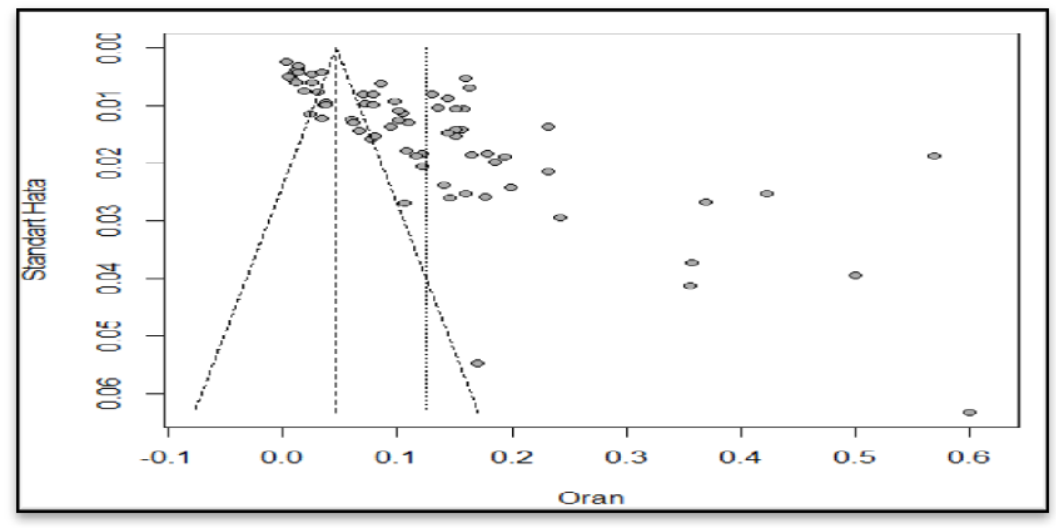

Şekil 2. İnternet bağımlılığı - huni diyagramı (funnel grafiği)

Şekil 2. incelendiğinde her bir çalışma eşit noktalarla gösterilmektedir. Yayın yanı olup olmadığını incelemek için doğrusal regresyon testi sonucunda $(\mathrm{p}=7.072 \mathrm{e}-13<$ $0.05)$ ve rank korelasyonu testi sonucunda ( $\mathrm{p}$ $=8.701 \mathrm{e}-07<0.05) \% 95$ güven ile yayın yanı olduğu söylenebilmektedir. Türkçe ile İngilizce yayınlanmış çalışmalar ele alındığından yayın yanlılığı beklenildiği gibi oluşmuştur.

İnternet bağımlılık oranının meta-analizi ile saptanmasında üç yaklaşıma göre veri analizleri yapılmıştır. Tablo 2' de normal dağılım, logit ve arcsin yöntemlerine göre elde edilen birleştirilmiş oran ve bu orana ilişkin güven aralıkları ile farkı verilmiştir.

İnternet bağımlılık oranının meta-analizi ile saptanmasındaki ilk yaklaşım, normal dağılıma yaklaşımdır.
Normal dağılıma yaklaşımda birleştirilmiş oran 0.1258 , alt sinır 0.1101 ve üst sinır 0.1415 şeklinde bulunmuştur. İnternet bağımlılık oranının meta-analizi ile saptanmasındaki ikinci yaklaşım Logit dönüşümdür. Logit dönüşüm için birleştirilmiş oran 0.0975 , alt sınır 0.0821 ve üst sınır 0.1156 şeklinde bulunmuştur. İnternet bağımlılık oranının meta-analizi ile saptanmasındaki üçüncü yaklaşım Arcsinüs dönüşümüdür. Arcsin dönüşüm için birleştirilmiş oran 0.1119 , alt sınır 0,0912 ve üst sınır 0,1344 şeklinde bulunmuştur.

Tablo 2'ye göre en küçük fark 0,0314 ile normal dağılım yaklaşım yöntemidir. Normal dağılıma yaklaşım yönteminin güven aralığı daha dar olduğu için Türkiye'deki internet bağımlılık oranı bu yöntemle analiz edilmiştir.

Tablo 2. Birleştirilmiş oran sonuçları ve güven aralıkları

\begin{tabular}{ccccc}
\hline Model & Birleştirilmiş Oran & Alt sınır & Üst sınır & Fark \\
\hline Normal Dağılım & 0,1258 & 0,1101 & 0,1415 & 0,0314 \\
Logit & 0,0975 & 0,0821 & 0,1156 & 0,034 \\
Arcsin & 0,1119 & 0,0912 & 0,1344 & 0,043 \\
\hline
\end{tabular}



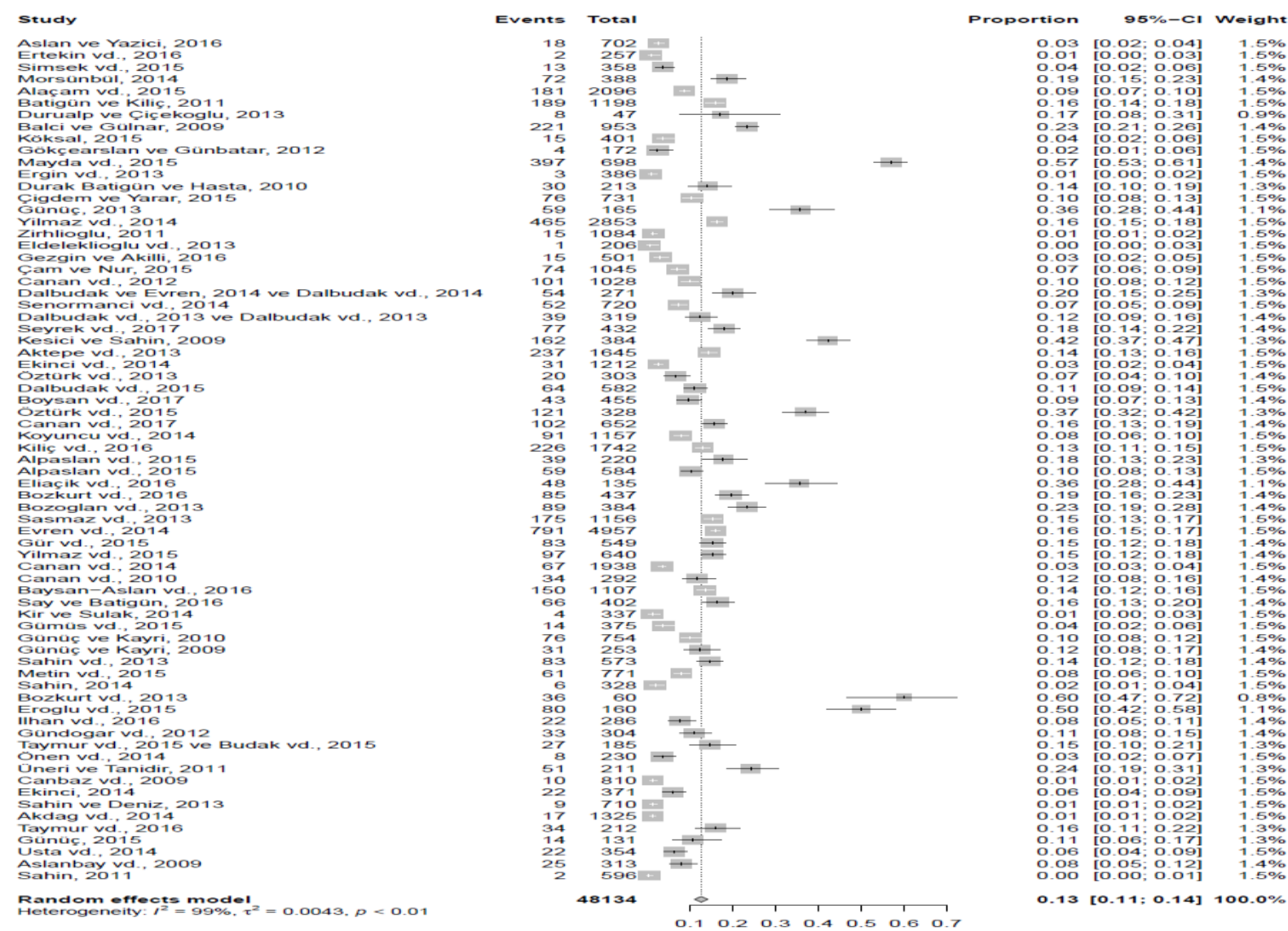

Şekil 3. Türkiye'deki internet bağımlılık oranı - forest grafiği

Tablo 3. Türkiye'nin coğrafi bölgelere göre alt grup analizi sonuçları

\begin{tabular}{cccc}
\hline Bölge & Çalışma Sayısı & $\begin{array}{c}\text { İnternet Bağımlılık } \\
\text { Oranı }\end{array}$ & Güven Aralı̆̆ı \\
\hline Akdeniz & 9 & 0.11 & $(0.07 ; 0.16)$ \\
Doğu Anadolu & 5 & 0.05 & $(0.03 ; 0.07)$ \\
Güneydoğu Anadolu & 1 & 0.03 & $(0.01 ; 0.06)$ \\
Karadeniz & 9 & 0.14 & $(0.08 ; 0.19)$ \\
Ege & 6 & 0.17 & $(0.10 ; 0.25)$ \\
Marmara & 11 & 0.13 & $(0.08 ; 0.18)$ \\
İç Anadolu & 16 & 0.17 & $(0.11 ; 0.22)$ \\
Diğer & 14 & 0.10 & $(0.07 ; 0.13)$ \\
\hline Toplam & $\mathbf{7 1}$ & $\mathbf{0 . 1 3}$ & $\mathbf{( 0 . 1 1 ; 0 . 1 4 )}$ \\
\hline
\end{tabular}

Dahil edilme ve dışlanma kriterlerine göre 71 büyüklüklerini gösteren forest grafiği çizimi çalışmaya ait internet bağımlılık oranları, Şekil 3'te verilmiştir.

$\% 95$ güven aralıklarını ve birleştirilmiş etki 
Forest grafiği çiziminde örneklem hacminin 47 ile 4957 arasında değiştiği gözlenmiştir. Toplam örneklem hacmi 48134'dür. Forest grafiği çizimindeki kare her bir çalışmadaki gözlenen etki, elmas ise birleştirilmiş etki büyüklüğünü göstermektedir. Elmasın genişliği güven aralığı ile ilişkilidir. Grafiğin ortasındaki kesikli çizgi güven aralığının yaygınlığını göstermektedir $(0.11 ; 0.14)$. Çalışmalar arası varyans 0.0043 olarak elde edilmiştir. Türkiye'deki internet bağımlılık oranı \%13' dir. Alt sınır 0,11 ve üst sınır 0,14 olarak hesaplanmıştır.

Heterojenlik incelendiğinde, etki büyüklüğünün çalışmalar arasında oldukça heterojen olduğu saptanmıştır $\left(I^{2}=\right.$ $\% 99.9, p=0.0001$, ve $\left.\tau^{2}=0,0043\right)$. Çalışmaların Heterojenliğin ortaya çıkarılmasında alt grup analizlerinden faydalanılmıştır.

Türkiye'nin coğrafi bölgelerine göre internet bağımlılığının incelenmesi için alt grup analizi yapılmıştır (Tablo 3). Burada çalışma alt grupları; Akdeniz Bölgesi, Doğu Anadolu Bölgesi, Ege Bölgesi, Karadeniz Bölgesi, Marmara Bölgesi, İç Anadolu Bölgesi, Güneydoğu Anadolu Bölgesi, diğer (İl belirtilmemiş, Ankara-İstanbul, İzmir-Edirne, Samsun-Van, Bandirma-Yozgat, AnkaraKırıkkale, İstanbul-Ankara-İzmir-DiyarbakırSamsun-Mersin-Van, Türkiye) olarak tanımlanmıştır.

Türkiye'nin coğrafi bölgelerine göre alt grup analizi sonucunda, coğrafi bölgeler bakımından heterojenlik olduğu görülmüştür. Etki büyüklüğü çalışmalar arasında çok değişmektedir $\left(I^{2}=\% 99\right)$.

Türkiye'nin çalışılan gruba göre internet bağımlılı̆̆ının incelenmesi için alt grup analizi yapılmıştır. Burada çalışılan alt gruplar üniversite, lise, ortaokul, liseortaokul ve diğer (ilkokul, meslek grubu, ilkokul-ortaokul-lise) olarak tanımlanmıştır.

Çalışma alt gruplarında etki büyüklüklerinin eşitliği \%95 güvenle reddedilmiştir $(p<$ 0.05) ve çalışma alt gruplarının heterojen olduklarına karar verilmiştir.

Türkiye'nin çalışma grubuna göre alt grup analizi sonucunda, çalışma grubu bakımından heterojenlik olduğu görülmüştür. Etki büyüklüğü çalışmalar arasında çok değişmektedir $\left(\mathrm{I}^{2}=\% 99\right)$.

Tablo 4. Türkiye' de çalışılan gruba göre alt grup analizi aonuçları

\begin{tabular}{cccc}
\hline Çalışılan Grup & Çalışma Sayısı & $\begin{array}{c}\text { İnternet Bağımlıık } \\
\text { Oranı }\end{array}$ & Güven Aralı̆̆ \\
\hline Ortaokul & 3 & 0.05 & $(0.01 ; 0.10)$ \\
Lise & 27 & 0.09 & $(0.07 ; 0.12)$ \\
Ortaokul-Lise & 8 & 0.30 & $(0.19 ; 0.40)$ \\
Üniversite & 30 & 0.13 & $(0.10 ; 0.16)$ \\
Diğer & 3 & 0.09 & $(0.00 ; 0.18)$ \\
\hline Toplam & $\mathbf{7 1}$ & $\mathbf{0 . 1 3}$ & $\mathbf{( 0 . 1 1 ; 0 . 1 4 )}$ \\
\hline
\end{tabular}




\section{Sonuç}

$\mathrm{Bu}$ çalışmada Türkiye'deki internet bağımlılık oranı, coğrafi bölgelere göre ve çalışılan gruplarına göre bağımlılık oranlarının saptanması için meta-analiz yöntemi uygulanmıştır.

Türkiye'de internet bağımlılı̆̆ konusunda yayımlanan çalışmalar meta-analizi ile incelenmiştir. 5 farklı veri tabanından "internet bağımlılı̆̆ı", "internet addiction", "problematic internet use", "problemli internet kullanımı", “IAS”, “IBÖ” anahtar kelimeleri ile yapılan araştırma sonucunda 4255 adet yayına ulaşılmıştır. Meta-analizine dahil edilecek çalışmaların dilinin Türkçe ve İngilizce olarak Türkiye'de yapılmış ve bağımlı kişi sayısının raporlanmış olmasına dikkat edilmiştir. Deneysel çalışmalar (araştırmacı tarafindan bağımlı-bağımlı olmayan gruplarında yer alacak kişilerin belirlendiği) ve tek vaka çalışmaları analiz dişında tutulmuştur. Çalışmalar arasındaki heterojenlik alt grup analizi ile saptanmıştır.

Dahil edilme ve dişlanma kriterlerine göre 71 çalışma ele alınmıştır. Homojenlik testinde heterojenliğin saptanmasından dolayı rastgele etkili model, normal dağılım, logit ve arcsinüs yöntemleri için uygulanmış ve en dar güven aralığını veren normal dağılım yöntemi tercih edilmiştir.

Heterojenlik incelemesinde, $\mathrm{Q}=4863,67$ ve $\mathrm{I}^{2}=\% 99,9$ elde edilmiştir $(\mathrm{p}<0,05) . \mathrm{Bu}$ nedenle çalışmaların oldukça heterojen olduğu saptanmıştır. Heterojenliğin ortaya çıkarılmasında alt grup analizlerinden faydalanılmıştır. Alt grup olarak Türkiye'nin coğrafi bölgeleri ile çalışılan grup ele alınmıştır.
Sonuç olarak, Türkiye'de internet bağımlılık oranı \%13 (\%95 GA: 0,11; 0,14) olarak saptanmıştır. Bölgeler incelendiğinde; Ege ve İç Anadolu bölgesi \%17, Karadeniz \%14, Marmara \%13, Akdeniz \%11, Doğu Anadolu $\% 5$ ve Güneydoğu Anadolu \%3 oranlarında internet bağımlılı̆̆ saptanmıştır.

Çalışılan grup incelendiğinde; ortaokul $\% 5$, lise $\% 9$, ortaokul-lise $\% 30$, üniversite $\% 13$ oranlarında internet bağımlılığı saptanmıştır.

Türkiye'de internet bağımlılık oranı metaanaliz yöntemiyle ilk kez incelenmiştir. "Bağımlılık" adı altında birçok meta-analiz çalışması yapılabilir. Teknolojik ilerlemeyle ortaya çıkan ve gençliğin ruhsal sağlığını hedef alan modern çağın yeni sorunları nomofobi (cep telefonundan mahrum kalma korkusu) ile netlessfobinin (internetsiz kalma korkusu), alkol bağımlılığı, sigara ve tütün bağımlılığ1, madde bağımlılı̆̆1, kumar bağımlılığı, telefon bağımlılığı gibi bağımlılık oranları araştırılabilir. Bunlarla ilgili yapılan literatür taramasında Türkiye'de yapılmış "Oran İçin Meta-analiz" çalışması olmadı̆̆ı görünmektedir.

\section{Kaynaklar}

Internet World Stats. (2017). http://www.internetworldstats.com. Son Erişim Tarihi: 14.05.2017.

Young, K. S. "Internet Addiction: A New Clinical Phenomenon and its Concequences". Behavior, 2004. 48.

Bayraktar, F. 2001 "İnternet Kullanımının Ergen Gelişimindeki Rolü”, Yayımlanmış Yüksek Lisans Tezi, Ege Üniversitesi Sosyal Bilimler Enstitüsü, İzmir, 10-25. 
Morahan-Martin, J. Schumacher, P. Schmidt, F. L. Hunter, J. E. "Development of "Incidence and Correlates of Pathological A General Solution to the Problem of Internet Use Among College Students". Validity Generalization". Journal of Applied Computers in Human Behavior. 2000. 16(1). Psychology. 1977. 1 (62), 529.

13-29.

Muslu, G. K. Bolisik, B. "Internet Usage Glass, G. V. McGraw, B. Smith, M. L. Among Children and Young People". TAF Prev Med Bull. 2009. 8(5). 445-50.

Caplan, S. E. "Problematic İnternet Use and Psychosocial Well-Being: Development of A Theory-Based Cognitive-Behavioral Measurement Instrument". Comput. Human Behav. 2002. 18(5). 553-75.

Welsh, L. 1999 "Internet Use: An Exploration of Coping Style, Locus of Control and Expectancies", Unpublished Doctoral Dissertation, Northeastern University, Boston, 15-30.

Shim, YS. 2004 "The Impact of the Internet on Teen-agers' Interpersonal Communication Behaviors: the Relation-ship Between Internet Use and Desire for Face-to-Face Communication", Unpublished Doctoral Dissertation, Southern Illinois University, Carbondale, 5-40.

Borenstein, M. Hedges, L. V. Higgins, J. Rothstein, H. R. (2009). "Computing Effect Sizes for Meta-analysis". Chishester: John Wiley \& Sons, Ltd. 45-60.

Pearson, K. "Report on Certain Enteric Fever Inoculation Statistics". $\mathrm{Br}$ Med J. 1904. 2(2288). 1243-46.

Rosenthal, R. Rubin, R. D. "Interpersonal Expectancy Effects: The First 345 Studies". Behavioral and Brain Sciences. 1978. 1 (3). 377. (1981). "Meta-analysis in Social Research". Thousand Oaks, CA: Sage. 12-16.

Hedges, L. V. Olkin, I. (1985). "Statistical Methods for Meta-analysis". San Diego, CA: Academic Press . 11-22.

Hunter, J. E., Schmidt, F. L. Jackson, G.B. (1982). "Meta-analysis: Cumulating Research Findings Across Studies". Beverly Hills, CA: Sage. 55-75.

Rosenthal, R. (1984). "Meta-Analytic Procedures For Social Research". Beverly Hills, CA: Sage. 45-50.

Deeks, J. J. "Issues İn The Selection Of A Summary Statistic For Meta Analysis of Clinical Trials With Binary Outcomes". Statistics in Medicine. 2002. 21. 1575-1600.

Sutton, A. J. Abrams, K. R. Jones, D. R. Sheldon, T. A. Song, F. "Methods for MetaAnalysis in Medical Research". John Wiley \& Sons. 76-89.

Huedo-Medina, T.B. Sanchez-Meca, J. Marin-Martinez, F. Botella, J. "Assessing Heterogeneity in Meta-analysis: Q Statistics or I I Index?". 2006. Psychological Methods. 2006. 11(2). 193.

Bailer III, J. C. Mosteller, F. (1992). "Reviews and Meta-Studies, Medical Uses of Statictics. 2nd ed." Boston, NEJM Boks.

Borenstein, M. Hedges, L. V. Higgins, J. P. Rothstein, H. R. (2013). "Meta-analize giriş, 
(Çev. S. Dinçer)", Anı Yayıncılık, Ankara. 110-130.

Dinçer, S. (2014). "Eğitim bilimlerinde uygulamalı meta-analiz". Pegem Akademi, Ankara. 38-50.

Nyaga, V.N. Arbyn, M. Aerts, M. "Metaprop: A Stata Command to Perform Meta-analysis of Binomial Data". Archives of public health. 2014. 72(39). 1-10.

Barendregt, J. J. Doi, S. A. Lee, Y. Y. Norman, R.E. Vos, T. "Meta-analysis of Pevalence". Epidemiol Community Health. 2013. 67. 974-978.

DerSimonian, R. Laird, N. "Meta-Analysis in Clinical Trials". Control Clin Trials. 1986. 7(3). 177-188.

Zhang, M.W. Ho, R.C. Cheung, M.W. Fu, E. Mak, A. "Prevalence of Depressive Symptomsin Patients with Chronic Obstructive Pulmonary Disease: A Systematic Review, Meta-Analysis and Meta-Regression" General Hospital Psychiatry. 2011. 33(3). 217-223.

Horikawa, C. Kodama, S. Yachi, Y. Heianza, Y. Hirasawa, R. Ibe, Y. "Skipping Breakfast and Prevalence of Overweight and Obesity in Asian and Pacific Regions: A Meta Analysis". Prevmed. 2011. 53(4-5). 260-267.

Barendregt, J. J. Doi, S. A. Lee, Y. Y. Norman, R.E. Vos, T. "Meta-analysis of Pevalence". Epidemiol Community Health. 2013. 67. 974-978.

http://strata.uga.edu/8370/rtips/proportions.ht ml. Son Erişim Tarihi: 12.04.2017.
Sokal, R.R. Rohlf, F.J. (1995) "Biometry: The Principles and Practice of Statistics in Biological Research. 3rd Edition". W.H. Freeman and Co., New York. 36-49.

Hanlon, B. Larget, B. (2011). Assumptions and Transformations. Department of Statistics University of Wisconsin, Madison.

Shao, J. (1998). "Mathematical Statistics". Springer, New York, New York, USA. 150178.

Vollset, S. E. "Confidence Intervals For A Binomial Proportion". Statistics in Medicine. 1993. 12. 809-824.

Blyth, C. R. Still, H. A. "Binomial Confdence Intervals". Journal of the American Statistical Association. 1983. 78, 108-116.

Aslan, E. Yazıc1, A. "Üniversite Öğrencilerinde İnternet Bağımlılığı ve İlişkili Sosyodemografik Faktörler". Klinik Psikiyatri. 2016. 19. 109-117.

Ertekin, Y. H. Ertekin, H. Uludağ, A. Tekin, M. "İlköğretim Sekizinci Sınıf Öğrencilerinde İnternet Bağımlılı̆̆ı: Çanakkale Örneklemi”. Türkiye Aile Hekimliği Dergisi. 2016. 20(2). 72-76.

Şimşek, N. Akça, N. K. Şimşek, M. "Lise Öğrencilerinde Umutsuzluk Ve İnternet Bağımlılı̆̆ı". TAF Preventive Medicine Bulletin. 2015. 14(1). 7-14.

Morsünbül, Ü. "Ergenlik Döneminde İnternet Bağımlılı̆̆ı: Kimlik Stilleri ve Seçeneklerin Saplantılı Araştırılması ile İlişkileri”. Anadolu Psikiyatri Dergisi. 2014. 15: 77-83. 
Alaçam, H. Ateşci-Çulha, F. Şengül, A. C. Tümkaya S. "Üniversite Öğrencilerinde İnternet Bağımlılığının Sigara ve Alkol Kullanımı ile İlişkisi”. Anadolu Psikiyatri Dergisi. 2015. 16(6). 383-388.

Batıgün-Durak, A. Kılıç, N. "İnternet Bağımlılığı ile Kişilik Özellikleri, Sosyal Destek, Psikolojik Belirtiler ve Bazı SosyoDemografik Değişkenler Arasındaki İlişkiler”. Türk Psikoloji Dergisi. 2011. 26 (67). 1-10.

Durualp, E. Çiçekoğlu, P. "Yetiştirme Yurdunda Kalan Ergenlerin Yalnızlık Düzeylerinin İnternet Bağımlılı̆̆ı ve Çeşitli Değişkenler Açısından İncelenmesi”. Dokuz Eylül Üniversitesi Sosyal Bilimler Enstitüsü Dergisi. 2013. 15(1). 29-46.

Balcı, Ş. Gülnar, B. "Üniversite Öğrencileri Arasında İnternet Bağımlılı̆̆ı ve İnternet Bağımlılarının Profili”. Selçuk İletişim. 2009. 6 (1). 5-22.

Köksal, Y. "İnternet Bağımlılı̆g İle İnternetten Alışveriş İlişkisi Üzerine Bir İncelenme; Üniversite Öğrencileri Uygulamas1". Mehmet Akif Ersoy Üniversitesi Sosyal Bilimler Enstitüsü Dergisi. 2015. 7(12). 117-130.

Gökçearslan, Ş. Günbatar, M. S. Zırhlığlu, G. “İnternet Bağımlılığının "Ortaöğrenim Öğrencilerinde İnternet Bağımlılı̆̆ı”. Ĕgitim Teknolojisi Kuram ve Uygulama. 2012. 2(2). 10-24.

Mayda, A. S. Yılmaz, M. Bolu, F. Dağlı, S. Ç. Gerçek, G. Ç. Teker, N. Tiryaki, S. Toygar, G. Türkarslan, M. Uslu, A. M. Usturalı E. Yamansavc1, E. Yardımc1, N. Önder, A. D. "Bir Öğrenci Yurdunda Kalan Üniversite Öğrencilerindeki İnternet Bağımlılığı ile Beck Depresyon Ölçeği
Arasındaki İlişki”. Konuralp Tip Dergisi. 2015. 7(1). 6-14.

Ergin, A. Uzun, S. U. Bozkurt, A. İ. "T1p Fakültesi Öğrencilerinde İnternet Bağımlılığ Sıklığı ve Etkileyen Etmenler". Pamukkale Tip Dergisi. 2013. 6(3). 134-142.

Batıün-Durak, A. Hasta, D. "İnternet Bağımlılığı: Yalnızlık ve Kişilerarası İlişki Tarzları Açısından Bir Değerlendirme". Anadolu Psikiyatri Dergisi. 2010. 11. 213219.

Çiğdem, H. Yarar, G. "Meslek Yüksekokulu Öğrencilerinin İnternet Bağımlılıkları ile İyilik Halleri Arasındaki İlişkinin İncelenmesi". Electronic Journal of Vocational Colleges. 2015. 72-81.

Günüç, S. "İnternet Bağımlılığını Yordayan Bazı Değişkenlerin Cart ve Chaid Analizleri ile İncelenmesi". Türk Psikoloji Dergisi. 2013. 28 (71). 88-101.

Yılmaz, E. Şahin, Y. L. Haseski, H. İ. Erol, O. "Lise Öğrencilerinin İnternet Bağımlılık Düzeylerinin Çeşitli Değişkenlere Göre İncelenmesi: Balıkesir İli Örneği”. Eğitim Bilimleri Araştırmaları Dergisi. 2014. 4(1). 133-144.

CHAID Analizi ile İncelenmesi: Van İli Örneğì". Eğitimde ve Psikolojide Ölçme ve Değerlendirme Dergisi. 2011. 2(2). 182-190.

Eldeleklioğlu, J. Batık- Vural, M. "Akademik Başarı, İnternette Kalınan Süre, Yalnızlık ve Utangaçlığın İnternet Bağımlılığ Üzerindeki Yordayıc1 Etkileri”. Hacettepe Üniversitesi Ĕ̈itim Fakültesi Dergisi. 2013. 28(1). 141152. 
Gezgin, D. M. Kaplan-Akıllı, G. "Lise Öğrencilerinin İnternet Bağımlılıklarının Çeşitli Değişkenler Açısından İncelenmesi”. Mersin Üniversitesi Eğitim Fakültesi Dergisi. 2016. 12(3). 917-931.

Çam, H. H. Nur, N. “Adölesanlarda İnternet Bağımlılığı Prevalansı ile Psikopatolojik Semptomlar ve Obezite Arasındaki İlişkinin İncelenmesi”. TAF Preventive Medicine Bulletin. 2015. 14(3). 181-188.

Canan, F. Ataoglu, A. Özcetin, A. Icmeli, C. "The Association Between Internet Addiction and Dissociation Among Turkish College Students". Comprehensive Psychiatry. 2012. 53. 422-426.

Dalbudak, E. Evren, C. "The Relationship of Internet Addiction Severity with Attention Deficit Hyperactivity Disorder Symptoms in Turkish University Students; Impact of Personality Traits, Depression and Anxiety". Comprehensive Psychiatry. 2014. 55. 497503.

Dalbudak, E. Evren, C. Aldemir, S. Evren, B. "The Severity of Internet Addiction Risk and Its Relationship with the Severity of Borderline Personality Features, Childhood Traumas, Dissociative Experiences, Depression and Anxiety Symptoms Among Turkish University Students". Psychiatry Research. 2014. 219. 577-582.

Şenormanc1, Ö. Saraçl1, Ö. Atasoy, N. Şenormanc1, G. Koktürk, F. Atik, L. "Relationship of Internet Addiction With Cognitive Style, Personality, and Depression in University Students". Comprehensive Psychiatry. 2014. 55. 1385- 1390.

Dalbudak, E. Evren, C. Topcu, M. Aldemir, S. Coskun, K. S. Bozkurt, M. Evren, B.
Canbal, M. "Relationship of Internet Addiction with Impulsivity and Severity of Psychopathology Among Turkish University Students". Psychiatry Research. 2013. 210. 1086-1091.

Dalbudak, E. Evren, C. Aldemir, S. Coşkun, K. S. Ugurlu, H. Yildirim, F. G. "Relationship of Internet Addiction Severity with Depression, Anxiety, and Alexithymia, Temperament and Character in University Students". Cyberpsychology, Behavior, and Social Networking. 2013. 16(4). 272-278.

Seyrek, S. Cop, E. Sinir, H. Uğurlu, M. Şenel, S. "Factors Associated With Internet Addiction: Cross-sectional Study of Turkish Adolescents". Pediatrics International. 2017. 59. 218-222.

Kesici, Ş. Şahin, İ. "A Comparative Study of Uses of the Internet Among College Students with and without Internet Addiction". Psychological Reports. 2009. 105(3). 11031112.

Aktepe, E. Dündar, N. O. Soyöz, Ö. Sönmez, Y. "Possible Internet Addiction in High School Students in The City Center of Isparta and Associated Factors: A Cross-sectional Study". The Turkish Journal of Pediatrics 2013. 55. 417-425.

Ekinci Ö. Çelik, T. Savaş, N. Toros, F. "Association Between Internet Use and Sleep Problems in Adolescents". Archives of Neuropsychiatry. 2014. 51. 122-128.

Ozturk, F. O. Ekinci, M. Ozturk, O. Canan, F. "The Relationship of Affective Temperament and Emotional-Behavioral Difficulties to Internet Addiction in Turkish Teenagers". ISRN Psychiatry. 2013. 
Dalbudak, E. Evren, C. Aldemir, S. Taymur, İ. Evren, B. Topcu, M. "The Impact of Sensation Seeking on the Relation Ship Between Attention Deficit/Hyperactivity Symptoms and Severity of Internet Addiction Risk". Psychiatry Research. 2015. 228. 156161.

Boysan, M. Kuss, D. J. Barut, Y. Ayköse, N. Güleç, M. Ozdemir O. "Psychometric Properties of the Turkish Version of the Internet Addiction Test (IAT)". Addictive Behaviors. 2017. 64. 247-252.

Öztürk, C. Bektas, M. Ayar, D. Öztornac1, B. Ö. Yağc1, D. "Association of Personality Traits and Risk of Internet Addiction in Adolescents". Asian Nursing Research. 2015. 9. 120-124.

Canan, F. Karaca, S. Düzgün, M. Erdem, A. M. Karaçaylı, E. Topan, N. B. Lee, S. K. Zhai, Z. W. Kuloğlu, M. Potenza, M. N. "The Relationship Between Second-to Fourth Digit (2D:4D) Ratios and Problematic and Pathological Internet Use Among Turkish University Students". Journal of Behavioral Addictions. 2017. 6(1). 30-41.

Koyuncu, T. Unsal, A. Arslantas, D. "Assessment of Internet Addiction and Loneliness in Secondary and High School Students". J Pak Med Assoc. 2014. 64. 9981002.

Kilic, M. Avci, D. Uzuncakmak T. "Internet Addiction in High School Students in Turkey and Multivariate Analyses of the Underlying Factors". Journal of Addictions Nursing. 2016. 27(1). 39-46.

Alpaslan, A. H. Soylu, N. Kocak, U. Guzel, H. I. "Problematic Internet Use Was More Common in Turkish Adolescents with Major
Depressive Disorders Than Controls". Acta Pcediatrica. 2015. 105. 695-700.

Alpaslan, A. H. Koçak, U. Avci, K. Taş, H. U. "The Association Between Internet Addiction and Disordered Eating Attitudes Among Turkish High School Students". Eat Weight Disord. 2015. 20. 441-448.

Eliacik, K. Bolat, N. Koçyiğit, C. Kanik, A. Selkie, E. Yilmaz, H. Catli, G. Dundar, N. O. Dundar, B. N. "Internet Addiction, Sleep and Health-Related Life Guality Among Obese Individuals: A Comparison Study of the Growing Problems in Adolescent Health". Eat Weight Disord. 2016. 21. 709-717.

Bozkurt, H. Özer, S. Şahin, S. Sönmezgöz, E. "Internet Use Patterns and Internet Addiction in Children and Adolescents with Obesity". Pediatric Obesity. 2016. 13(5). 301-306.

Bozoglan, B. Demirer, V. Sahin, I. "Loneliness, Self-Esteem, and Life Satisfaction as Predictors of Internet Addiction: A Cross-Sectional Study Among Turkish University Students". Scandinavian Journal of Psychology. 2013. 54. 313-319.

Şaşmaz, T. Öner, S. Kurt, A. Ö. Yapıcı, G. Yazıc1, A. E. Buğdayc1, R. Şiş, M. "Prevalence and Risk Factors of Internet Addiction in High School Students". European Journal of Public Health. 2013. 24(1). 15-20.

Evren, C. Dalbudak, E. Evren, B. Demirci, A. C. "High Risk of Internet Addiction and Its Relationship with Lifetime Substance Use, Psychological and Behavioral Problems Among 10th Grade Adolescents". Psychiatria Danubina. 2014. 26(4). 330-339. 
Gür, K. Yurt, S. Bulduk, S. Atagöz, S. "Internet Addiction and Physical and Psychosocial Behavior Problems Among Rural Secondary School Students". Nursing and Health Sciences. 2015. 17. 331-338.

Yılmaz, S. Hergüner, S. Bilgiç, A. Işık, Ü. "Internet Addiction is Related to Attention Deficit but not Hyperactivity in a Sample of High School Students". Internatiol Journal of Psychiatry in Clinical Practice. 2015. 19. 18-23.

Canan, F. Yildirim, O. Ustunel, T. Y. Sinani, G. Kaleli, A. H. Gunes, C. Ataoglu, A. "The Relationship Between Internet Addiction and Body Mass Index in Turkish Adolescents". Cyberpsychology, Behavior, and Social Networking. 2014. 17(1). 40-45.

Canan, F. Ataoglu, A. Nichols, L. A. Yildirim, O. Ozturk O. "Evaluation of Psychometric Properties of the Internet Addiction Scale in a Sample of Turkish High School Students". Cyberpsychology, Behavior, and Social Networking. 2010. 13(3). 317-320.

Arslan, S. B. Cebeci, S. Kaya, M. Canbal, M. "Relationship Between Internet Addiction and Alexithymia Among University Students". Clin Invest Med. 2016. 39(6). S111-S115.

Say, G. Batıün, A. D. "The Assessment of the Relationship Between Problematic Internet Use and Parent-Adolescent Relationship Quality, Loneliness, Anger, and Problem Solving Skills". The Journal of Psychiatry and Neurological Sciences. 2016. 29(4). 324-334.

Kır, İ. Sulak, Ş. "Eğitim Fakültesi Öğrencilerinin İnternet Bağımlılık
Düzeylerinin İncelenmesi”. Elektronik Sosyal Bilimler Dergisi. 2014. 13(51). 150-167.

Gümüş, A. B. Şıpkın, S. Tuna, A. Keskin, G. "Üniversite Öğrencilerinde Problemli İnternet Kullanımı, Şiddet Eğilimi ve Bazı Demografik Değişkenler Arasındaki İlişki”. TAF Preventive Medicine Bulletin. 2015. 14(6). 460-467.

Günüç, S. Kayri, M. “Türkiye'de İnternet Bağımlılık Profili ve İnternet Bağımlılık Ölçeğinin Geliştirilmesi: Geçerlik-Güvenirlik Çalışması". Hacettepe Üniversitesi Eğitim Fakültesi Dergisi. 2010. 39. 220-232.

Günüç, S. Kayri, M. “İnternet Bağımlılık Ölçeğinin Türkçeye Uyarlanması: Geçerlik ve Güvenirlik Çalışması”. Ankara Üniversitesi Eğitim Bilimleri Fakültesi Dergisi. 2009. 42(1). 157-175.

Sahin, S. Ozdemir, K. Unsal, A. "Evaluation of the Relationship Between Internet Addiction and Depression in University Students". Medicinski Glasnik. 2013. 14-27.

Metin, O. Saracl1, O. Atasoy, N. Senormanc1, O. Kardes, V. C. Acikgöz, H. O. Demirci, E. Ayan, U. B. Atik, L. Tahiroglu, A. Y. "Association of Internet Addiction in High School Students with ADHD and Tobacco/Alcohol Use". The Journal of Psychiatry and Neurological Sciences. 2015. 28(3). 204-212.

Sahin, M. "The Internet Addiction and Aggression Among University Students". The Journal of Psychiatry and Neurological Sciences. 2014. 27(1). 43-52.

Bozkurt, H. Coskun, M. Ayaydın, H. Adak, İ. Zoroglu, S. S. "Prevalence and Patterns of Psychiatric Disorders in Referred 
Adolescents with Internet Addiction". Psychiatry and Clinical Neurosciences. 2013. 67. 352-359.

Eroğlu, Y. Aktepe, E. Akbaba, S. Işı1k, A. Özkorumak, E. "The Investigation of Prevalence and Risk Factors Associated with Cyber Bullying and Victimization". Education and Science. 2015. 40(177). 93107.

İlhan, A. Çelik, H. C. Gemcioğlu, M. Çiftaslan, M. E. "Examination of the Relationship Between Internet Attitudes and Internet Addictions of 13-18-Year-Old Students: The Case of Kahramanmaraş". The Turkish Online Journal of Educational Technology. 2016. 15(2). 73-77.

Gündogar, A. Bakim, B. Ozer, O. A. Karamustafalioglu, O. "The Association Between Internet Addiction, Depression and Adhd Among High School Students". 20th European Congress of Psychiatry. 2012.

Taymur, İ. Budak, E. Askin, R. Gungor, B. B. Akgul, A. I. Anil -Sahin, Z. "Relationship Between Internet Addiction, Psychopathology and Self-Esteem in University Student". Bulletin of Clinical Psychopharmacology. 2015. 25(1). S75.

Budak, E. Taymur, İ. Askin, R. Gungor, B. B. Demirci, H. Akgul, A. I. Anil -Sahin, Z. "Relationship Between Internet Addiction, Psychopathology and Self-Esteem Among University Students". The European Research Journal. 2015. 1(3). 128-135.

Önen, C. Tunçdemir, A. Özer, A. "Internet Addiction of Students at the Vocational High School of Healthcare". Bitlis Eren University Journal of Science \& Technology. 2014. 4(2). 23-25.
Üneri, Ö. Ş. Tanıdır, C. "Evaluation of Internet Addiction in a Group of High School Students: A Cross-sectional Study”. Düşünen Adam Psikiyatri ve Nörolojik Bilimler Dergisi. 2011. 24(4). 265-272.

Canbaz, S. Tevfik-Sunter, A. Peksen, Y. Canbaz, M. A. "Prevalence of the Pathological Internet Use in a Sample of Turkish School Adolescents". Iranian J Publ Health. 2009. 38(4). 64-71.

Ekinci, B. "The Relationship Between Problematic Internet Entertainment Use and Problem Solving Skills Among University Students". International Journal of Mental Health \& Addiction. 2014. 12. 607-617.

Sahin, M. Deniz, L. "Internet Addiction Among Turkish Primary School Students". Journal of Instructional Psychology. 2013. 40(4). 101-103.

Akdağ, M. Yılmaz, B. Ş. Özhan, U. Şan, İ. "Investigation of University Students' Internet Addiction in Terms of Several Variables (Inonu University Sample)". Inönü University Journal of the Faculty of Education. 2014. 15(1). 73-96.

Taymur, I. Budak, E. Demirci, H. AkdağAlkan, H. Güngör, B. B. Özdel, K. "A Study of the Relationship Between Internet Addiction, Psychopathology and Dysfunctional Beliefs". Computers in Human Behavior. 2016. 61. 532-536.

Gunuc, S. "Relationships And Associations Between Video Game and Internet Addictions: Is Tolerance A Symptom Seen in All Conditions". Computers in Human Behavior. 2015. 49. 517-525. 
Usta, E. Korkmaz, Ö. Kurt, İ. "The Examination of Individuals' Virtual Loneliness States in Internet Addiction and Virtual Environments in Terms of InterPersonal Trust Levels". Computers in Human Behavior. 2014. 36. 214-224.

Aslanbay, Y. Aslanbay M. Çobanoğlu, E. "Internet Addiction Among Turkish Young Consumers". Young Consumers. 2009. 10(1). 60-70.

Şahin, C. “An Analysis of Internet Addiction Levels of Individuals According to Various Variables". The Turkish Online Journal of Educational Technology. 2011. 10(4). 60-66. 